\title{
Effect of Slip Conditions and Entropy Generation Analysis with an Effective Prandtl Number Model on a Nanofluid Flow through a Stretching Sheet
}

\author{
Mohammad Mehdi Rashidi ${ }^{1}$ and Munawwar Ali Abbas ${ }^{2, *}$ \\ 1 Department of Civil Engineering, University of Birmingham, Edjbaston, Birmingham B15 2TT, UK; \\ m.m.rashidi@bham.ac.uk \\ 2 Department of Computer Science, Karakoram International University, Skardu Campus, \\ Gilgit Baltistan 16100, Pakistan \\ * Correspondence: munawerabbas@yahoo.com; Tel.: +92-344-2312630
}

Received: 14 July 2017; Accepted: 9 August 2017; Published: 11 August 2017

\begin{abstract}
This article describes the impact of slip conditions on nanofluid flow through a stretching sheet. Nanofluids are very helpful to enhance the convective heat transfer in a boundary layer flow. Prandtl number also play a major role in controlling the thermal and momentum boundary layers. For this purpose, we have considered a model for effective Prandtl number which is borrowed by means of experimental analysis on a nano boundary layer, steady, two-dimensional incompressible flow through a stretching sheet. We have considered $\gamma \mathrm{Al}_{2} \mathrm{O}_{3}-\mathrm{H}_{2} \mathrm{O}$ and $\mathrm{Al}_{2} \mathrm{O}_{3}-\mathrm{C}_{2} \mathrm{H}_{6} \mathrm{O}_{2}$ nanoparticles for the governing flow problem. An entropy generation analysis is also presented with the help of the second law of thermodynamics. A numerical technique known as Successive Taylor Series Linearization Method (STSLM) is used to solve the obtained governing nonlinear boundary layer equations. The numerical and graphical results are discussed for two cases i.e., (i) effective Prandtl number and (ii) without effective Prandtl number. From graphical results, it is observed that the velocity profile and temperature profile increases in the absence of effective Prandtl number while both expressions become larger in the presence of Prandtl number. Further, numerical comparison has been presented with previously published results to validate the current methodology and results.
\end{abstract}

Keywords: heat transfer; entropy; Prandtl number; nanofluid; slip effects

\section{Introduction}

Motivated scientists and researchers have identified the present age as an industrial and technological era. Thus, several theoretical and experimental studies have been undertaken to enhance the performance of industrial production methods. Researchers have identified that heat transfer is essential for the excellence of large scale processes. Usually, thermal characteristics are attained through conventional fluids but limited heat transfer capabilities have imposed a restriction on their utilization. Therefore, engineers thought that improved heat transfer routines should be implemented in order to achieve the desired outputs. For this purpose, they have performed several hypothetical and thought-provoking studies. Finally, they came up with the notion that the thermal ability of a carrier fluid can be improved with the escalation of its thermal conductance. Consequently, the idea of introducing particles into the basic fluid to provide a better transfer medium was introduced. The dimensions of these supplementary nanoparticles have attracted substantial interest due to their distinctive physical and chemical features. Now, it is well-established fact that the inclusion of nanomaterials enhances the thermal performance and conductivity of ordinary fluids. Thus, the dynamics of convective heat transport phenomenon via nanoparticles has grasped the focus of enthusiastic workers due to their incredible and extensive demand. 
Choi [1] was the first to mention the idea of nanofluids. He defined nano liquids as an engineered dispersion of nanoparticles in a carrier fluid. He proved through experiments that the thermal capability of the host liquid is boosted with the addition of these small-sized materials. Masuda et al. [2] estimated the disparities in both thermal conductivity and the viscosity of conventional fluids by the dispersal of ultrafine particles in the host fluid. He reconfirmed that thermal transport in ordinary fluids increases tremendously with the suspension of ultrafine structures. Buongiorno [3] did seminal work on nanofluids by presenting a speculative model in order to interrogate the thermal features of carrier fluids. He contemplated that the improvement in conductance of regular fluid is due to the low volume fraction and small size of added nanoelements. Actually, nanotechnology is of great significance in numerous fields, including transportation, metallurgical and chemical devices, manufacturing of microscale objects, generation of power, cancer therapy, etc. The investigation on nanofluid flow over linearly stretched sheets was primarily initiated by Khan and Pop [4]. They numerically investigated the impact of the thermophoretic force and Brownian movement of nanostructures on thermal conductivity of the fluid. MHD stagnation boundary layer flow with collaborated effects of convective mode of heating, Brownian movement and thermophoretic force overstretched sheet were probed by Makinde et al. [5]. Nadeem et al. [6] performed numerical analysis of the magnetohydrodynamic flow of Maxwell fluids past a stretching sheet in the presence of nanoparticles. Malik et al. [7] performed a computational study to explore the effects of nanoparticles on an Eyring-Powel fluid model. Raju and Sandeep [8] addressed thermal and concentration transport due to Casson nanofluids in a rotating frame. Saleem and Nadeem [9] performed a comprehensive homotopy analysis to anticipate the impact of higher grade nanofluids over a rotatory cone. Raju et al. [10] conducted a comparative study to evaluate the fabulous enhancement in host fluid properties considering various types of metallic nanostructures. He also depicted the collaborative effects of temperature-dependent viscosity. A few recent studies exploring the the characteristics of nanofluids may be found in [11-15].

New resources to improve the heat transfer properties are becoming very important in many industrial applications. The study of heat transfer is not limited to an industrial application but also in much other applications such as wire drawing, metal spinning aerodynamics extrusion of plastic sheets and hot rolling. Utilization of solid nanoscale particles in working liquids is considered one of the most advanced techniques for improving their heat transfer characteristics. Several investigations have been made the effect of heat transfer in a nanofluid. Radiative heat transfer of nanofluids with variant surface heat flux and the effects of chemically reacting species were demonstrated by Zhang et al. [16]. Nield and Kuznetsov [17] capitalized on the Buongiorno model to adumbrate convective heat transfer induced by vertically stretched surfaces immersed in a Darcy medium. They reported that the strength of the heat transfer rate decreases by escalating the Brownian motion and thermophoresis parameters. The collective heat and mass features over a permeable exponentially stretched surface with second order slip were discussed by Rahman et al. [18]. Bhatti et al. [19] examined the numerical simulation of fluid flow over a shrinking sheet with heat transfer. Moreover, some more investigations of heat transfer with different geometries such as stretching sheet can be viewed in [20-24].

In 1996 Bejan [25] employed the second law of thermodynamics by means of entropy generation minimization. He covered the entropy generation minimization, particularly in the field of storage, heat transfer, thermal science and thermal power conversion. The thermodynamics approach plays a vital role in optimizing thermal engineering devices for higher energy efficiency. For this purpose, the minimization of entropy generation is used to determine the level of the available irreversibility in a process. These discussions clearly indicate that second law of thermodynamics is more reliable than the first law to determine the efficiency in the heat transfer system. Much more attention needs to be paid to optimize the heat transfer in electronic devices and engineering systems. Abbas et al. [26] studied the minimization of entropy generation of the peristaltic flow of nanofluid by using an analytical technique. Entropy generation of a Casson nanofluid over a stretching sheet has been analyzed by Abolbashari et al. [27]. For further works about entropy generation of nanofluids, one can refer to [28-32]. 
At present, not much work has been mentioned about entropy generation of nanofluids over a stretching sheet in the presence of slip effects. With all this in mind, the aim of the current work was to analyze the impact of entropy generation in the presence of Prandtl number and slip conditions through a stretching sheet.

\section{Mathematical Formulation}

Let us consider a two-dimensional steady irrotational, incompressible $\gamma \mathrm{Al}_{2} \mathrm{O}_{3}-\mathrm{H}_{2} \mathrm{O}$ and $\mathrm{Al}_{2} \mathrm{O}_{3}-\mathrm{C}_{2} \mathrm{H}_{6} \mathrm{O}_{2}$ nanofluid flow through a vertical stretching surface coinciding with a plane at $y=0$. To derive the governing equations, Cartesian coordinates system has been taken with the $x$-axis considered as vertically upward. The nanofluid flow occurs due to a stretching of a sheet caused by a pair of opposite and equal forces along the $x$-axis. The stretching sheet velocity can be written as $\widetilde{u}_{w}=a x$ and the temperature at a stretching sheet is $\widetilde{T}_{w}=b x+\widetilde{T}_{\infty}$. Where $\widetilde{T}_{\infty}$ is the ambient temperature, $a$ and $b$ are constants. The governing equations for the heat transfer for a nanofluid and steady boundary layer convective flow can be described as [19]:

$$
\begin{gathered}
\frac{\partial \check{v}}{\partial y}+\frac{\partial \check{u}}{\partial x}=0 \\
\left(\check{v} \frac{\partial \check{u}}{\partial y}+\check{u} \frac{\partial \check{u}}{\partial x}\right) \rho_{n f}=\left(\check{T}-T_{\infty}\right) g[\rho \beta]_{n f}+\mu_{n f} \frac{\partial^{2} \breve{u}}{\partial y^{2}}
\end{gathered}
$$

Their respective boundary conditions are given by:

$$
\check{T}=\check{T}_{w}(x), \quad \check{u}=\check{u}_{w}+\kappa \frac{\partial \check{u}}{\partial \check{y}}, \check{y}=0, \text { as } \check{T} \rightarrow \check{T}_{\infty}, y \rightarrow \infty \check{u} \rightarrow 0,
$$

\section{Thermophysical Properties of $\gamma \mathrm{Al}_{2} \mathrm{O}_{3}-\mathrm{H}_{2} \mathrm{O}$ and $\mathrm{Al}_{2} \mathrm{O}_{3}-\mathrm{C}_{2} \mathrm{H}_{6} \mathrm{O}_{2}$ Nanofluids}

The heat capacitance $\left(\rho C_{p}\right)_{n f}$, the effective dynamic viscosity $\rho_{n f}$ and the coefficient of thermal expansion $(\rho \beta)_{n f}$ of a nanofluid are described as:

$$
\begin{gathered}
\rho_{n f}=\rho_{f}(1-\varphi)+\rho_{s} \phi, \\
\left(\rho C_{p}\right)_{n f}=\phi\left(\rho C_{p}\right)_{s}+\left(\rho C_{p}\right)_{f} \cdot 1-\phi\left(\rho C_{p}\right)_{f} \\
(\rho \beta)_{n f}=\phi(\rho \beta)_{s}+(\rho \beta)_{f}-\phi(\rho \beta)_{f}
\end{gathered}
$$

where, the nanofluid volume fraction in solid form is denoted as $\phi$.

(i) Dynamic viscosity model:

$$
\begin{gathered}
\frac{\mu_{n f}}{\mu_{f}}=123 \phi^{2}+7.3 \phi+1, \text { for } \gamma \mathrm{Al}_{2} \mathrm{O}_{3}-\mathrm{H}_{2} \mathrm{O} \\
\frac{\mu_{n f}}{\mu_{f}}=306 \phi^{2}-0.19 \phi+1, \text { for } \gamma \mathrm{Al}_{2} \mathrm{O}_{3}-\mathrm{C}_{2} \mathrm{H}_{6} \mathrm{O}_{2}
\end{gathered}
$$

(ii) Effective thermal conductivity model:

$$
\begin{gathered}
\frac{\kappa_{n f}}{\kappa_{f}}=[\phi(4.97 \phi+2.72)+1], \text { for } \gamma \mathrm{Al}_{2} \mathrm{O}_{3}-\mathrm{H}_{2} \mathrm{O} \\
\frac{k_{n f}}{k_{f}}=28.905 \phi^{2}+2.8273 \phi+1, \text { for } \gamma \mathrm{Al}_{2} \mathrm{O}_{3}-\mathrm{C}_{2} \mathrm{H}_{6} \mathrm{O}_{2}
\end{gathered}
$$


(iii) Effective Prandtl number model:

$$
\begin{gathered}
\frac{\operatorname{Pr}_{n f}}{\operatorname{Pr}_{f}}=82.1 \phi^{2}+3.9 \phi+1, \text { for } \gamma \mathrm{Al}_{2} \mathrm{O}_{3}-\mathrm{H}_{2} \mathrm{O} \\
\frac{\operatorname{Pr}_{n f}}{\operatorname{Pr}_{f}}=254.3 \phi^{2}-3 \phi+1, \text { for } \gamma \mathrm{Al}_{2} \mathrm{O}_{3}-\mathrm{C}_{2} \mathrm{H}_{6} \mathrm{O}_{2}
\end{gathered}
$$

To compute the specific heat for nanofluids and the density, Equation (4) is derived for this purpose. In Equations (5) and (6), the expression for a dynamic viscosity of nanofluid is obtained by means of least-squares curve fitting of a few scarce experimental results that can be viewed for considered mixtures [33,34]. Equations (7) and (8) are presented from a model presented by Hamilton and Crosser [35], associated the nanofluids thermal conductivity, however, the similar case also exists for $\gamma \mathrm{Al}_{2} \mathrm{O}_{3}$ nanofluids [36]. Equations (9) and (10) describe the effective Prandtl number for $\gamma \mathrm{Al}_{2} \mathrm{O}_{3}$ nanofluids which are obtained with the help of a curve fitting by means of regression laws [37].

By introducing the similarity variables as:

$$
\xi=\sqrt{\frac{a}{v_{f}}} y, \widetilde{u}=a x f^{\prime}(\zeta), \widetilde{v}=-\sqrt{a v_{f}} f(\xi), \theta(\zeta)=\frac{\widetilde{T}-\widetilde{T}_{\infty}}{\widetilde{T}_{w}-\widetilde{T}_{\infty}} .
$$

Using these transformations in Equations (2) and (3), we get:

$$
\begin{gathered}
\left(123 \phi^{2}+7.3 \phi+1\right) f^{\prime \prime \prime}+\left(f f^{\prime \prime}-f^{\prime 2}\right)\left(1-\phi+\phi \frac{\rho_{s}}{\rho_{f}}\right)+\lambda \theta\left(1-\phi+\phi \frac{(\rho \beta)_{s}}{(\rho \beta)_{f}}\right)=0, \text { for } \gamma \mathrm{Al}_{2} \mathrm{O}_{3}-\mathrm{H}_{2} \mathrm{O} \\
\left(306 \phi^{2}-0.19 \phi+1\right) f^{\prime \prime \prime}+\left(f f^{\prime \prime}-f^{\prime 2}\right)\left(1-\phi+\phi \frac{\rho_{s}}{\rho_{f}}\right)+\lambda \theta\left(1-\phi+\phi \frac{(\rho \beta)_{s}}{(\rho \beta)_{f}}\right)=0, \text { for } \gamma \mathrm{Al}_{2} \mathrm{O}_{3}-\mathrm{C}_{2} \mathrm{H}_{6} \mathrm{O}_{2} \\
\theta^{\prime \prime}+\Theta\left(f \theta^{\prime}-f^{\prime} \theta\right)=0,
\end{gathered}
$$

where:

$$
\begin{gathered}
\Theta=\frac{\operatorname{Pr}_{f}\left(1-\phi+\phi \frac{\rho_{s}}{\rho_{f}}\right)\left(82.1 \phi^{2}+3.9 \phi+1\right)}{123 \phi^{2}+7.3 \phi+1}, \\
\Theta=\frac{\operatorname{Pr}_{f}\left(1-\phi+\phi \frac{\rho_{s}}{\rho_{f}}\right)\left(254.3 \phi^{2}-3 \phi+1\right)}{306 \phi^{2}-0.19 \phi+1}, \\
\Theta=\frac{\operatorname{Pr}_{f}\left(1-\phi+\phi \frac{\rho_{s}}{\rho_{f}}\right)}{4.97 \phi^{2}+2.72 \phi+1}, \\
\Theta=\frac{\operatorname{Pr}_{f}\left(1-\phi+\phi \frac{\rho_{s}}{\rho_{f}}\right)}{28.905 \phi^{2}+2.8273 \phi+1},
\end{gathered}
$$

and $\lambda=g \beta_{f} b / a^{2}$ is a mixed convection parameter.

The new form of the boundary conditions as:

$$
f^{\prime}(0)=\beta f^{\prime}(0)+1, f^{\prime}(\infty)=0, \theta(\infty)=0, \theta(0)=1, f(0)=0
$$

where slip parameter $\beta=\frac{\kappa \sqrt{a}}{\sqrt{ }^{v} f}$.

It is worth mentioning that from Equations (15) and (16) the effective Prandtl number for $\gamma \mathrm{Al}_{2} \mathrm{O}_{3}-\mathrm{H}_{2} \mathrm{O}$ and $\gamma \mathrm{Al}_{2} \mathrm{O}_{3}-\mathrm{C}_{2} \mathrm{H}_{6} \mathrm{O}_{2}$ respectively, can be deduced. Similarly, the effective Prandtl number is mentioned in Equations (17) and (18) for $\gamma \mathrm{Al}_{2} \mathrm{O}_{3}-\mathrm{H}_{2} \mathrm{O}$ and $\gamma \mathrm{Al}_{2} \mathrm{O}_{3}-\mathrm{C}_{2} \mathrm{H}_{6} \mathrm{O}_{2}$ respectively. 


\section{Important Physical Quantities}

In the current study, the two most important physical quantities for the flow problem are the Nusselt number and skin friction coefficient which can be described as:

$$
C_{f}=\frac{-2 \mu_{n f}}{\rho_{f} u_{w}^{2}}\left(\frac{\partial \widetilde{u}}{\partial y}\right)_{y=0}
$$

the dimensionless form of the skin friction coefficient defined as:

$$
\begin{gathered}
C_{f} \frac{R e^{1 / 2}}{2}=-[\phi(123 \phi+7.3)+1] f^{\prime \prime \prime}(0), \text { for } \gamma \mathrm{Al}_{2} \mathrm{O}_{3}-\mathrm{H}_{2} \mathrm{O} \\
\frac{1}{2} \operatorname{Re}^{1 / 2} C_{f}=-\left(306 \phi^{2}-0.19 \phi+1\right) f^{\prime \prime}(0), \text { for } \gamma \mathrm{Al}_{2} \mathrm{O}_{3}-\mathrm{C}_{2} \mathrm{H}_{6} \mathrm{O}_{2}
\end{gathered}
$$

where $\operatorname{Re}=\frac{\widetilde{u}_{w}(x) x}{v_{f}}$ is a local Reynolds number and it depends upon the stretching velocity $\widetilde{u}_{w}(x)$ and $\operatorname{Re}_{x}^{1 / 2}$ is the skin friction coefficient. The Nusselt number is defined as:

$$
N u_{x}=\frac{-x \kappa_{n f}}{\left(\check{T}_{w}-\check{T}_{\infty}\right)}\left(\frac{\partial \check{T}}{\partial y}\right)_{y=0}
$$

Using Equations (11) and (23), we have:

$$
\begin{gathered}
\operatorname{Re}^{-1 / 2} N u_{x}=-\left(4.97 \phi^{2}+2.72 \phi+1\right) \theta^{\prime}(0), \text { for } \gamma \mathrm{Al}_{2} \mathrm{O}_{3}-\mathrm{H}_{2} \mathrm{O} \\
\operatorname{Re}^{-1 / 2} N u_{x}=-\left(28.905 \phi^{2}+2.8273 \phi+1\right) \theta^{\prime}(0), \text { for } \gamma \mathrm{Al}_{2} \mathrm{O}_{3}-\mathrm{C}_{2} \mathrm{H}_{6} \mathrm{O}_{2}
\end{gathered}
$$

\section{Entropy Generation Analysis}

The entropy generation for a nanofluid can be written as [38-43]:

$$
N_{G}=\frac{\kappa_{n f}}{\check{T}_{\infty}^{2}}\left[\left(\frac{\partial \check{T}}{\partial x}\right)^{2}+\left(\frac{\partial \check{T}}{\partial y}\right)^{2}\right]+\frac{\mu_{n f}}{\check{T}_{\infty}}\left(\frac{\partial \check{u}}{\partial y}\right)^{2}
$$

In the above volumetric rate of entropy generation equation, the first term represents entropy generation caused by heat transfer along a finite temperature difference. However, the second term reveals the entropy generation occurs due to viscous dissipation. The dimensionless form of entropy generation $N_{g}$ describes the ratio between the local volumetric entropy generation rate $N_{G}$ to a characteristic rate of entropy generation $\left(N_{g}\right)_{0}$. The characteristic entropy generation rate is described as:

$$
\left(N_{g}\right)_{0}=\frac{\kappa_{n f}(\Delta \breve{T})^{2}}{x^{2} \breve{T}_{\infty}^{2}}
$$

By taking the ratio of Equations (26) and (27) the entropy generation number can be written as:

$$
N_{g}=\frac{N_{G}}{\left(N_{g}\right)_{0}}
$$

Using Equations (11) and (26), we get:

$$
\begin{gathered}
N_{g}=\theta^{2}(\xi)+\theta^{\prime 2}(\xi) \operatorname{Re}+\left[\frac{123 \phi^{2}+7.3 \phi+1}{4.97 \phi^{2}+2.97 \phi+1}\right] \frac{B r}{\Omega} \operatorname{Re} f^{\prime \prime 2}(\xi), \text { for } \gamma \mathrm{Al}_{2} \mathrm{O}_{3}-\mathrm{H}_{2} \mathrm{O} \\
N_{g}=\theta^{2}(\xi)+\theta^{\prime 2}(\xi) \operatorname{Re}+\left[\frac{306 \phi^{2} 0-0.19 \phi+1}{28.905 \phi^{2}+2.8273 \phi+1}\right] \frac{B r}{\Omega} \operatorname{Re} f^{\prime \prime 2}(\xi), \text { for } \gamma \mathrm{Al}_{2} \mathrm{O}_{3}-\mathrm{C}_{2} \mathrm{H}_{6} \mathrm{O}_{2}
\end{gathered}
$$


where $\Omega$ is dimensionless temperature difference while Br indicates Brinkmann number, defined as:

$$
B_{r}=\frac{\mu_{f}{\widetilde{u_{w}}}^{2}}{\kappa_{f} \Delta \check{T}}, \Omega=\frac{\Delta \check{T}}{\check{T}_{\infty}}
$$

\section{Numerical Method}

To proceed with STSLM, let us consider:

$$
f(\xi)=f_{I}(\xi)+\sum_{N=0}^{I-1} f_{N}(\xi),(I=1,2,3, \ldots)
$$

In the above equation, $f_{I}$ is the unknown functions that can be solved iteratively using the linearized governing equations and consider the $f_{I}\{0 \leq N \leq I-1\}$ are known through the previous iteration.

Equations (12) and (13) can be written in the following form:

$$
L(\text { linear part })+N(\text { nonlinear part })=0,
$$

where:

$$
L\left[\left(123 \phi^{2}+7.3 \phi+1\right) f^{\prime \prime \prime}\right]+N\left[\left(f f^{\prime \prime}-f^{\prime 2}\right)\left(1-\phi+\phi \frac{\rho_{s}}{\rho_{f}}\right)+\lambda \theta\left(1-\phi+\phi \frac{(\rho \beta)_{s}}{(\rho \beta)_{f}}\right)\right]=0,
$$

for $\gamma \mathrm{Al}_{2} \mathrm{O}_{3}-\mathrm{H}_{2} \mathrm{O}$

$$
L\left[\left(306 \phi^{2}-0.19 \phi+1\right) f^{\prime \prime \prime}\right]+N\left[\left(f f^{\prime \prime}-f^{\prime 2}\right)\left(1-\phi+\phi \frac{\rho_{s}}{\rho_{f}}\right)+\lambda \theta\left(1-\phi+\phi \frac{(\rho \beta)_{s}}{(\rho \beta)_{f}}\right)\right]=0,
$$

for $\gamma \mathrm{Al}_{2} \mathrm{O}_{3}-\mathrm{C}_{2} \mathrm{H}_{6} \mathrm{O}_{2}$.

Using Equations (32), (12) and (13), we have:

$$
\begin{gathered}
A_{2, I-1} f_{I}+A_{1, I-1} f^{\prime}{ }_{I}+A_{0, I-1} f^{\prime \prime}{ }_{I}+f^{\prime \prime \prime}{ }_{I}=r_{I-1}, \\
B_{2, I-1} f_{I}+B_{I, I-1} f^{\prime}{ }_{I}+B_{0, I-1} f^{\prime \prime}{ }_{I}+f^{\prime \prime \prime}{ }_{I}=r_{I-1},
\end{gathered}
$$

along with their following boundary conditions in Equation (19). To obtain the subsequent solution for $f_{N}(N \geq 1)$, Equation (34) can be solved iteratively. For this purpose, the algorithm initiated with an initial guess and with the help of initial approximation. The ith-order approximation solution for $f(\xi)$ can be written as:

$$
f(\xi) \approx \sum_{N=0}^{I} f_{N}(\xi)
$$

To get the solution for Equation (35), Chebyshev spectral collocation method is used. It is worth to mentioned that the right-hand side of Equation (34) for various values of $i$ and by using the previous iterations we can get the coefficient of each parameter. Chebyshev spectral collocation method consists on the Chebyshev interpolating polynomials as given by:

$$
C_{K}(\eta)=\cos \left\{\frac{K}{\cos (\varsigma)}\right\}
$$

The interval for the above Chebyshev interpolating polynomials are given in the region $[-1,1]$. For the implications of this method and to convert the physical infinite region into the finite region we have applied a domain truncation method from the infinite region to a finite region as i.e., 
$[0, \infty) \rightarrow[-1,1]$, and this way the targeted solution can be achieved in the interval $[0, l]$ instead of $[0, \infty)$. This leads to the mapping:

$$
2 \varsigma=l(\eta+1),-1 \leq \eta \leq 1,
$$

It can be observed from Equation (37) that to invoke boundary conditions expressed at infinity, we used the scaling parameter " $l$ ". Gauss-Lobatto collocation points have applied to define the Chebyshev nodes in $[-1,1]$. With the help of interpolating polynomial at each collocation points and truncated Chebyshev series, the inspection of the variable $f_{I}$ is examined. The series obtained from truncated Chebyshev is given as:

$$
f_{I}(\eta)=\sum_{K=0}^{i} f_{I}\left(\eta_{K}\right) C_{K}\left(\eta_{J}\right), J=0,1 \ldots i
$$

where $C_{K}$ is the $K^{\text {th }}$ Chebyshev polynomials. The derivatives of the variables at collocation points can be written as:

$$
\frac{\mathrm{d}^{p} f_{I}}{\mathrm{~d} \varsigma^{p}}=\sum_{K=0}^{i} \mathbf{D}_{K J}^{p} f_{I}\left(\eta_{K}\right), J=0,1 \ldots i,
$$

In the above Equation (39) the terms $p$ and $\mathbf{D}$ are the order of differential matrix and Chebyshev spectral differentiation matrix, respectively. Using Equations (38) and (39) into Equation (34) we have:

$$
A_{I-1} G_{I}=\phi_{I-1} .
$$

where:

$$
\begin{gathered}
A_{I-1}=\left(A_{1, i-1}-M \mathbf{I}\right) \mathbf{D}+\mathbf{D}^{2} A_{0, I-1}+\mathbf{D}^{3}+A_{2, i-1}, \\
G_{I}=\left[f_{I}\left(\eta_{0}\right), f_{I}\left(\eta_{1}\right), \ldots f_{I}\left(\eta_{i}\right)\right]^{t}, \\
\breve{\phi}_{I-1}=\left\{\breve{\phi}_{-}(I-1)\left(\eta_{-} 0\right), \breve{\phi}_{-}(I-1)\left(\eta_{-} 1\right), \ldots . . \breve{\phi}_{-}(I-1)\left(\eta_{-} i\right),\right\}^{t}
\end{gathered}
$$

In the above equations, the terms $t, A_{K, I-1}$ and $(i+1) \times(i+1)$, represent the transpose, diagonal matrix of size and identity matrix, respectively. The $\mathrm{BC} f_{I}\left(\eta_{i}\right)=0$, is employed by removing the last column and last row of $A_{I-1}$ and by removing the last rows of $G_{I}$ and $\phi_{I-1}$. Setting the last and first rows of $\breve{\phi}_{I-1}$ and $G_{I}$ to be zero. The solution for $f_{I}\left(\eta_{1}\right), f_{I}\left(\eta_{2}\right), \ldots, f_{I}\left(\eta_{i-1}\right)$ are iteratively obtained after solving:

$$
G_{I}=A_{I-1}{ }^{-1} \breve{\phi}_{I-1}
$$

It is worth to mentioned also that after obtaining the solution from Equation (41), we can apply directly the Chebyshev pseudo-spectral method to Equation (14) we have:

$$
Z A=B
$$

With their relevant boundary conditions:

$$
\theta\left(\eta_{0}\right)=0, \quad \theta\left(\eta_{i}\right)=1,
$$

where $Z$ is the set linear differential equations and $A$ is the corresponding boundary conditions and $B$ is a vector of zeros. The obtained boundary conditions from Equation (43) is followed by the first and last rows of $B$ and $Z$, respectively.

\section{Results and Discussion}

This section describes the numerical and graphical results against all the governing parameters involved in the present flow problem. To analyze the proposed technique named Successive Taylor 
Series Linearization Method (STSLM), we have presented a comparison with previously published results and it is seen that the present results are in excellent agreement, which ensures the validity of the present methodology. In this methodology, the appropriate number of collocation points is considered as $i=70$ while the suitable value of $l$ is considered to be $l=20$. It is analyzed that the values of the parameters mentioned above are the best ever results as far as the current flow is concerned, moreover, the present findings are in excellent agreement with the published results. STSLM is computationally quite efficient and accurate in comparison with other numerical methods as it provides precise results prominently when a governing problem is directly solved. Table 1 represents the thermo-physical properties of alumina, ethylene glycol and water whereas Table 2 reveals the numerical comparison of $-\theta^{\prime}(0)$ with previously published results [44-46]. Table 3 shows skin friction coefficient for various values of Prandtl number and the numerical results of Nusselt number and mixed convection parameter. Figures 1-10 are sketched for different values of Prandtl number $\operatorname{Pr}$ slip parameter $\beta$, volume fraction of nano particle $\phi$, mixed convection parameter $\lambda$, Brinkmann number $B r$ and Reynolds number Re etc. against velocity profile $f^{\prime}(\xi)$, temperature profile $\theta^{\prime}(\xi)$ and entropy profile $N_{g}$.

Table 1. Properties of thermo-physical alumina, water and ethylene glycol.

\begin{tabular}{|c|c|c|c|c|}
\hline & $C_{p}(\mathrm{~J} / \mathrm{kg} \cdot \mathrm{K})$ & $\beta \times 10^{-5}\left(\mathrm{~K}^{-1}\right)$ & $\rho\left(\mathrm{kg} / \mathrm{m}^{3}\right)$ & $k(\mathrm{~W} / \mathrm{m} \cdot \mathrm{K})$ \\
\hline Water $\left(\mathrm{H}_{2} \mathrm{O}\right)$ & 4182 & 20.06 & 998.3 & 0.60 \\
\hline Ethylene glycol $\left(\mathrm{C}_{2} \mathrm{H}_{6} \mathrm{O}_{2}\right)$ & 2382 & 65 & 1116.6 & 0.249 \\
\hline Alumina $\left(\mathrm{Al}_{2} \mathrm{O}_{3}\right)$ & 765 & 0.85 & 3970 & 40 \\
\hline
\end{tabular}

Table 2. Numerical comparison of $-\theta^{\prime}(0)$ with previously published results.

\begin{tabular}{cccccc}
\hline$\lambda$ & Pr & Ali [34] & Grubka and Bobba [35] & Ishak et al. [36] & Present Results \\
\hline 0 & 0.72 & 0.8058 & 0.8086 & 0.8086 & 0.80883 \\
& 1 & 1.0000 & 1.0000 & 1.0000 & 1.00001 \\
& 3 & 1.9237 & 1.9144 & 1.9237 & 1.92368 \\
& 7 & & & 3.0723 & 3.07225 \\
& 10 & 3.7006 & 3.7207 & 3.7207 & 3.72067 \\
& 100 & & 12.2940 & 12.2941 & 12.29408 \\
1 & 1 & & & 1.0873 & 1.08728 \\
2 & & & & 1.1423 & 1.14234 \\
3 & & & & 1.1853 & 1.18528 \\
\hline
\end{tabular}

Table 3. Local Nusselt number and Skin friction coefficient, Numerical values.

\begin{tabular}{|c|c|c|c|c|c|c|c|c|}
\hline \multirow[b]{3}{*}{$\operatorname{Pr}$} & \multicolumn{2}{|c|}{${ }_{2}^{1} R e^{-0.5} C_{f}$} & \multicolumn{2}{|c|}{$R e^{-0.5} N u_{x}$} & \multicolumn{2}{|c|}{$\frac{1}{2} R e^{-0.5} C_{f}$} & \multicolumn{2}{|c|}{$R e^{-0.5} N u_{x}$} \\
\hline & \multicolumn{4}{|c|}{ For $\gamma \mathrm{Al}_{2} \mathrm{O}_{3}-\mathrm{H}_{2} \mathrm{O}$} & \multicolumn{4}{|c|}{ For $\mathrm{Al}_{2} \mathrm{O}_{3}-\mathrm{C}_{2} \mathrm{H}_{6} \mathrm{O}_{2}$} \\
\hline & $\begin{array}{l}\text { With } \\
\text { Effective } \\
\text { Prandtl } \\
\text { Parameter }\end{array}$ & $\begin{array}{l}\text { Without } \\
\text { Effective } \\
\text { Prandtl } \\
\text { Parameter }\end{array}$ & $\begin{array}{l}\text { With } \\
\text { Effective } \\
\text { Prandtl } \\
\text { Parameter }\end{array}$ & $\begin{array}{l}\text { Without } \\
\text { Effective } \\
\text { Prandtl } \\
\text { Parameter }\end{array}$ & $\begin{array}{l}\text { With } \\
\text { Effective } \\
\text { Prandtl } \\
\text { Parameter }\end{array}$ & $\begin{array}{l}\text { Without } \\
\text { Effective } \\
\text { Prandtl } \\
\text { Parameter }\end{array}$ & $\begin{array}{l}\text { With } \\
\text { Effective } \\
\text { Prandtl } \\
\text { Paramet }\end{array}$ & $\begin{array}{l}\text { Without } \\
\text { Effective } \\
\text { Prandtl } \\
\text { Paramet }\end{array}$ \\
\hline 1 & 1.29991 & 1.28495 & 1.25372 & 0.78594 & 1.43666 & 1.39986 & 27.6293 & 14.0726 \\
\hline 3 & 1.31432 & 1.30461 & 2.30596 & 1.49072 & 1.45995 & 1.43458 & 50.1784 & 26.4527 \\
\hline 6.96 & 1.32164 & 1.31481 & 3.60726 & 2.36655 & 1.4718 & 1.45394 & 78.076 & 41.9535 \\
\hline 10 & 1.32407 & 1.31821 & 4.35964 & 2.87282 & 1.47573 & 1.46041 & 94.2088 & 50.9162 \\
\hline
\end{tabular}

Figures 1-3 are sketched for the velocity profiles against multiple values of the slip parameter $\beta$, mixed convection parameter $\lambda$, and volume fraction of nanoparticles $\phi$. It is observed in Figure 1 that the slip parameter significantly reduces the velocity profile for both $\gamma \mathrm{Al}_{2} \mathrm{O}_{3}-\mathrm{C}_{2} \mathrm{H}_{6} \mathrm{O}_{2}$ and $\gamma \mathrm{Al}_{2} \mathrm{O}_{3}-\mathrm{H}_{2} \mathrm{O}$ nanofluids. However, in the absence of an effective Prandtl number, the velocity profile rises. Figure 2 shows the variation of velocity against multiple values of the mixed convection parameter $\lambda$. In this 
figure, we can see that the mixed convection parameter $\lambda$ does do not cause any major effect on $\gamma \mathrm{Al}_{2} \mathrm{O}_{3}-\mathrm{C}_{2} \mathrm{H}_{6} \mathrm{O}_{2}$ and $\gamma \mathrm{Al}_{2} \mathrm{O}_{3}-\mathrm{H}_{2} \mathrm{O}$ nanofluids. Mixed convection parameter $\lambda$ enhances the velocity profile in the absence and presence of effective Prandtl number. Figure 3 depicts the effect of nanoparticle volume fraction $\phi$ on velocity. The results for single-phase flow can be reduced by taking $\phi \rightarrow 0$ in the governing equations.

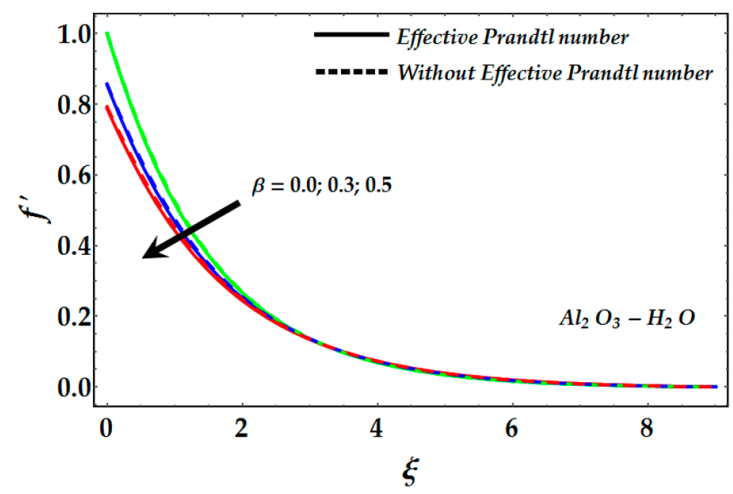

(a)

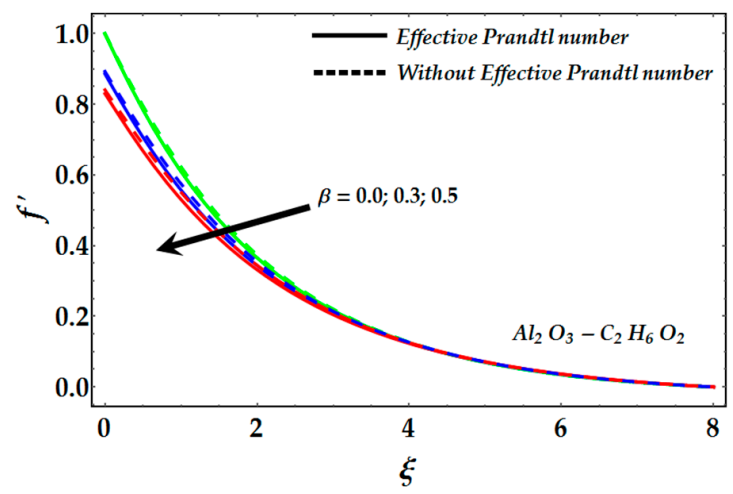

(b)

Figure 1. Velocity curves for different values of $\beta$. (a) For $\mathrm{Al}_{2} \mathrm{O}_{3}-\mathrm{H}_{2} \mathrm{O}$, (b) For $\mathrm{Al}_{2} \mathrm{O}_{3}-\mathrm{C}_{2} \mathrm{H}_{6} \mathrm{O}_{2}$.

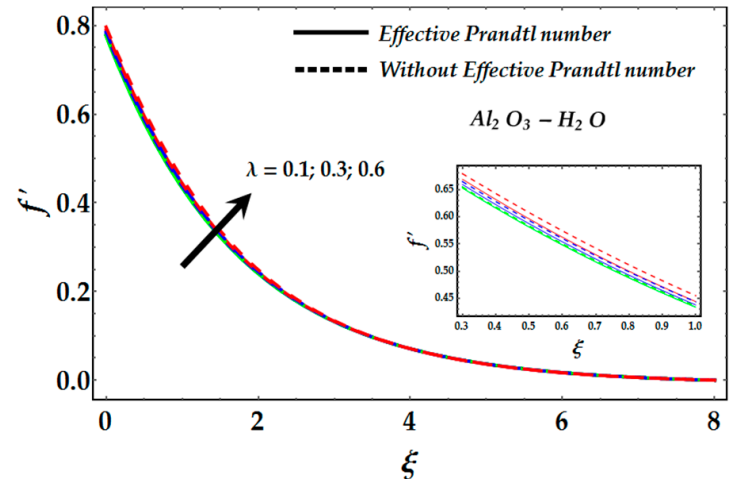

(a)

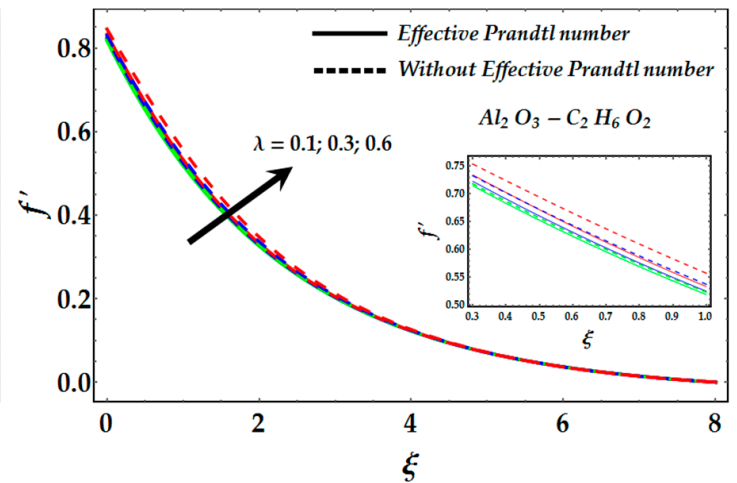

(b)

Figure 2. Velocity curves for different values of $\lambda$. (a) For $\mathrm{Al}_{2} \mathrm{O}_{3}-\mathrm{H}_{2} \mathrm{O}$, (b) For $\mathrm{Al}_{2} \mathrm{O}_{3}-\mathrm{C}_{2} \mathrm{H}_{6} \mathrm{O}_{2}$.

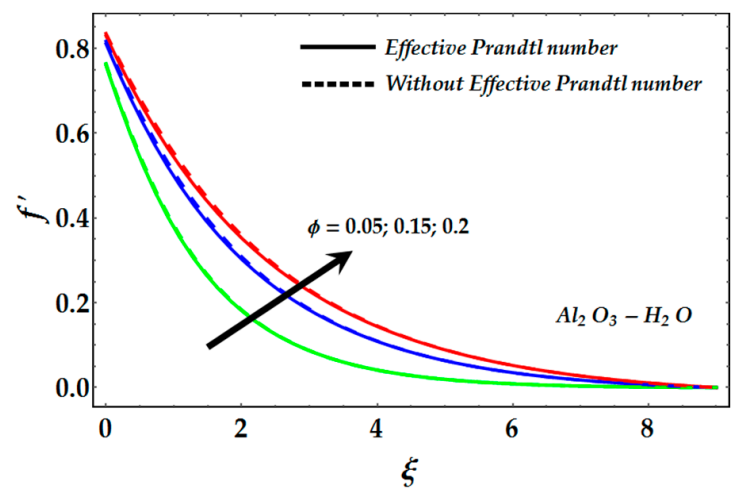

(a)

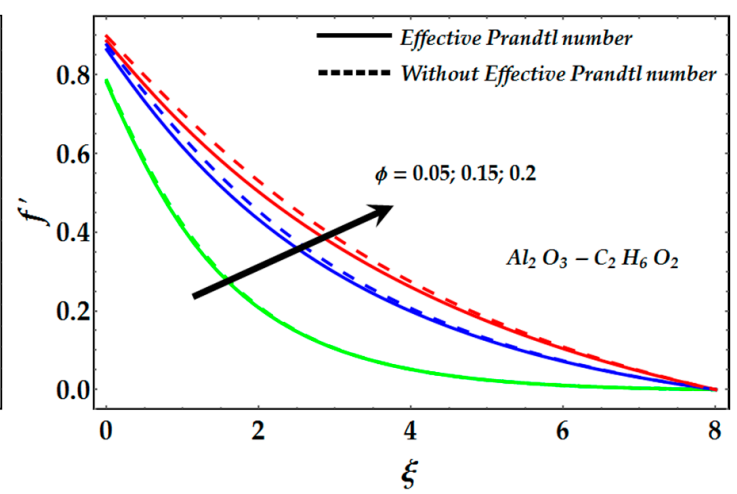

(b)

Figure 3. Velocity curves for different values of $\phi$. (a) For $\mathrm{Al}_{2} \mathrm{O}_{3}-\mathrm{H}_{2} \mathrm{O}$, (b) For $\mathrm{Al}_{2} \mathrm{O}_{3}-\mathrm{C}_{2} \mathrm{H}_{6} \mathrm{O}_{2}$.

In these figures, we can see that the nanoparticle volume fraction $\phi$ significantly boost the velocity profiles, however, there is not significant effect of effective Prandtl number on $\gamma \mathrm{Al}_{2} \mathrm{O}_{3}-\mathrm{H}_{2} \mathrm{O}$ fluid, whereas for $\gamma \mathrm{Al}_{2} \mathrm{O}_{3}-\mathrm{C}_{2} \mathrm{H}_{6} \mathrm{O}_{2}$ fluid the effective Prandtl number tends to diminish the velocity more 
significantly as compared to $\gamma \mathrm{Al}_{2} \mathrm{O}_{3}-\mathrm{H}_{2} \mathrm{O}$ fluid. Figures 4-6 displayed the behavior of temperature profile against Prandtl number $\mathrm{Pr}$, Slip parameter $\beta$, and nanoparticle volume fraction $\phi$. Figure 4 depicts that reduction in temperature profile for both $\gamma \mathrm{Al}_{2} \mathrm{O}_{3}-\mathrm{C}_{2} \mathrm{H}_{6} \mathrm{O}_{2}$ and $\gamma \mathrm{Al}_{2} \mathrm{O}_{3}-\mathrm{H}_{2} \mathrm{O}$ nanofluids for larger values of Prandtl number Pr. Prandtl number is helpful to control the relative thickness of the thermal and momentum boundary layers in heat transfer cases. The heat diffuses more rapidly as compared to velocity in the presence of a small Prandtl number. However, the greater impact of Prandtl number reveals that momentum diffusivity is more dominating over thermal diffusivity. Figure 5 is sketched for different values of slip parameter $\beta$. In this figure, we can see that the slip effects causes marked increment in the temperature profile for both $\gamma \mathrm{Al}_{2} \mathrm{O}_{3}-\mathrm{C}_{2} \mathrm{H}_{6} \mathrm{O}_{2}$ and $\gamma \mathrm{Al}_{2} \mathrm{O}_{3}-\mathrm{H}_{2} \mathrm{O}$ nanofluids. Figure 6 represents the variation of nanoparticle volume fraction $\phi$ on temperature profile. It can be viewed from Figure 6 that the temperature profiles for both $\gamma \mathrm{Al}_{2} \mathrm{O}_{3}-\mathrm{C}_{2} \mathrm{H}_{6} \mathrm{O}_{2}$ and $\gamma \mathrm{Al}_{2} \mathrm{O}_{3}-\mathrm{H}_{2} \mathrm{O}$ nanofluids increase when the Prandtl number does not exist, however, the behavior becomes quite the contrary in the presence of an effective Prandtl number. In Figures 4-6 we find that the magnitude of the temperature profile is significantly lower in the presence of an effective Prandtl number.

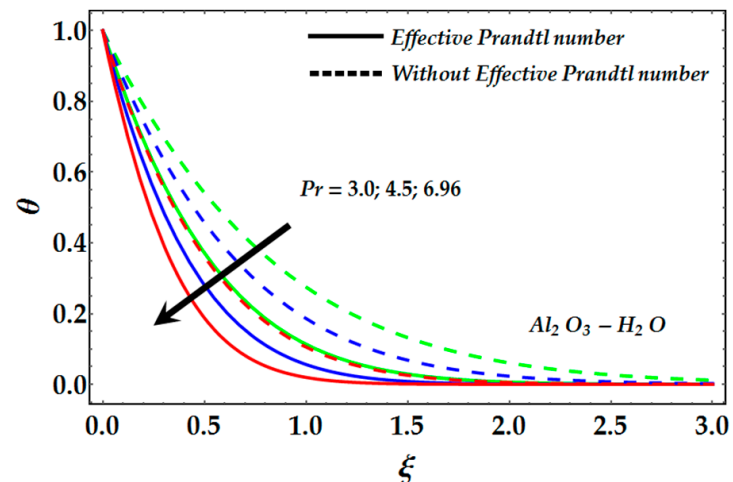

(a)

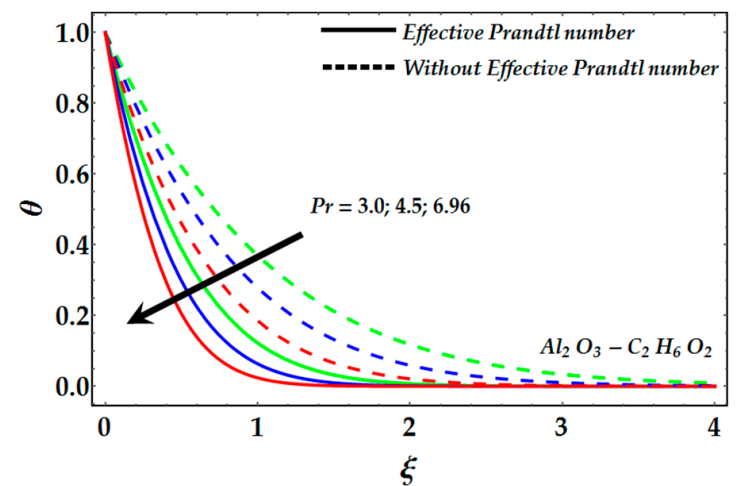

(b)

Figure 4. Temperature distribution for different values of Pr. (a) For $\mathrm{Al}_{2} \mathrm{O}_{3}-\mathrm{H}_{2} \mathrm{O}$, (b) For $\mathrm{Al}_{2} \mathrm{O}_{3}-\mathrm{C}_{2} \mathrm{H}_{6} \mathrm{O}_{2}$.

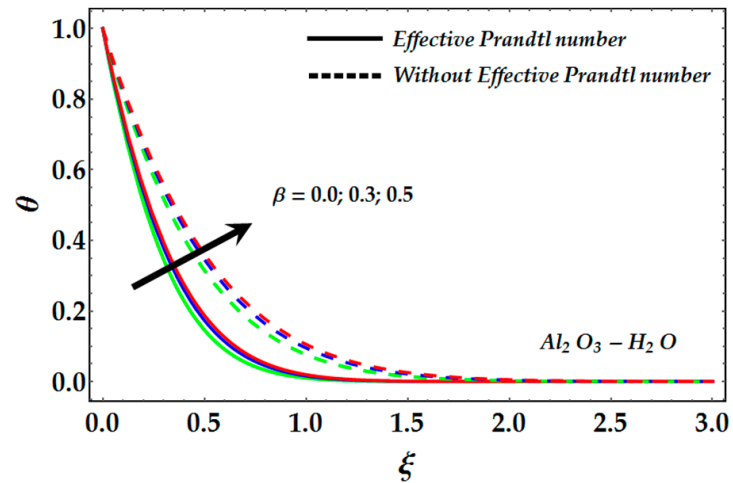

(a)

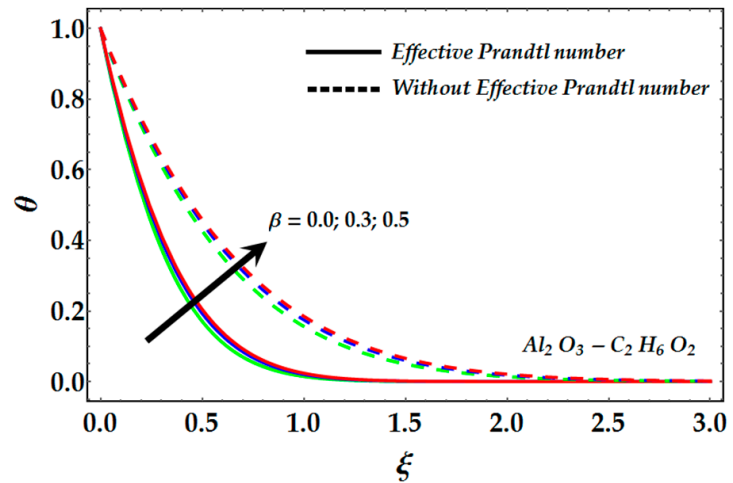

(b)

Figure 5. Temperature distribution for different values of $\beta$. (a) For $\mathrm{Al}_{2} \mathrm{O}_{3}-\mathrm{H}_{2} \mathrm{O}$, (b) For $\mathrm{Al}_{2} \mathrm{O}_{3}-\mathrm{C}_{2} \mathrm{H}_{6} \mathrm{O}_{2}$. 


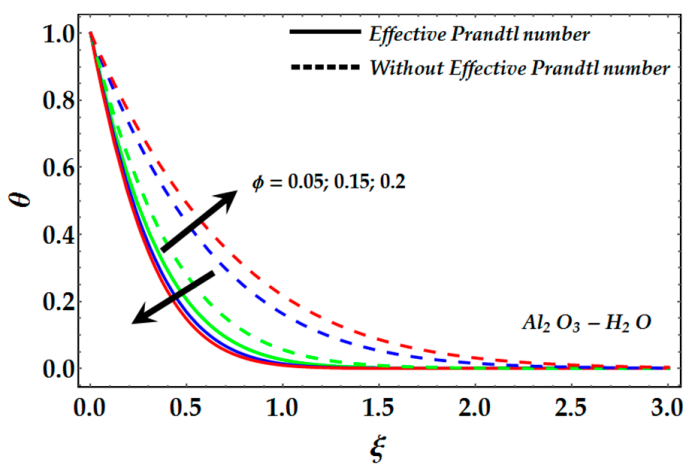

(a)

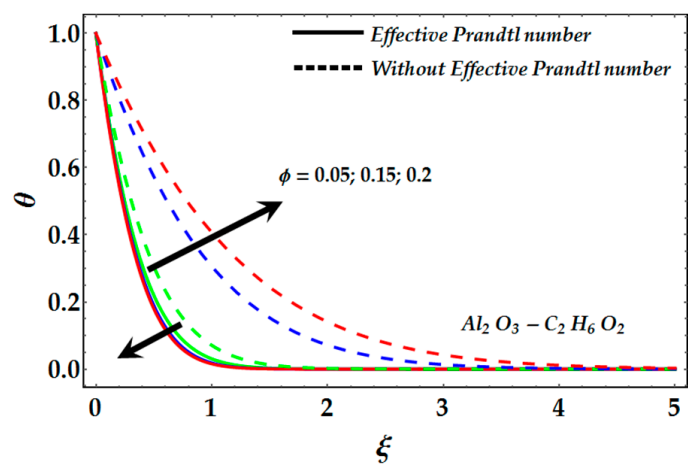

(b)

Figure 6. Temperature distribution for different values of $\phi$. (a) For $\mathrm{Al}_{2} \mathrm{O}_{3}-\mathrm{H}_{2} \mathrm{O}$, (b) For $\mathrm{Al}_{2} \mathrm{O}_{3}-\mathrm{C}_{2} \mathrm{H}_{6} \mathrm{O}_{2}$.

Figures 7-10 elucidate the behavior of the entropy profile against the various values of slip parameter $\beta$, volume fraction of nanoparticles $\phi$, Brinkmann number $\mathrm{Br}$ and Reynolds number Re. It can be observed from Figure 7 that an increment in slip parameter $\beta$, significantly enhances the entropy profile. However, it is found that in the presence of effective Prandtl number the entropy profile rises for $\gamma \mathrm{Al}_{2} \mathrm{O}_{3}-\mathrm{C}_{2} \mathrm{H}_{6} \mathrm{O}_{2}$ and $\gamma \mathrm{Al}_{2} \mathrm{O}_{3}-\mathrm{H}_{2} \mathrm{O}$ nanofluids. Figure 8 depicts that the entropy profile increases for higher values of the nanoparticle volume fraction $\phi$ in the presence of an effective Prandtl number whereas the behavior is contrary in the absence of an effective Prandtl number. An interesting thing observed here that in the absence of an effective Prandtl number, the entropy profile changes its behavior when $\xi>0.5$ for both $\gamma \mathrm{Al}_{2} \mathrm{O}_{3}-\mathrm{C}_{2} \mathrm{H}_{6} \mathrm{O}_{2}$ and $\gamma \mathrm{Al}_{2} \mathrm{O}_{3}-\mathrm{H}_{2} \mathrm{O}$ nanofluids.

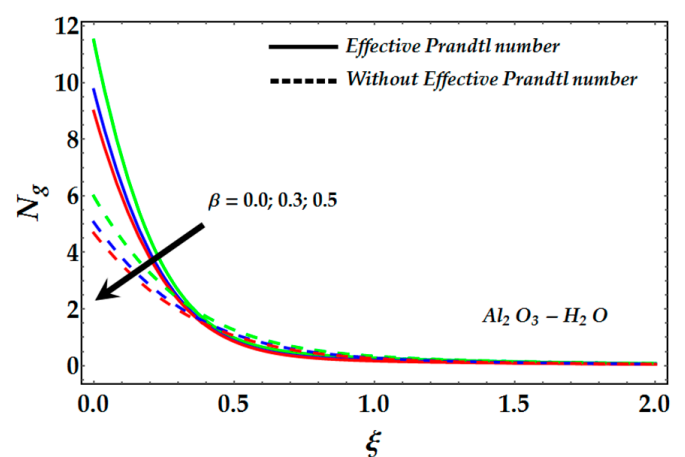

(a)

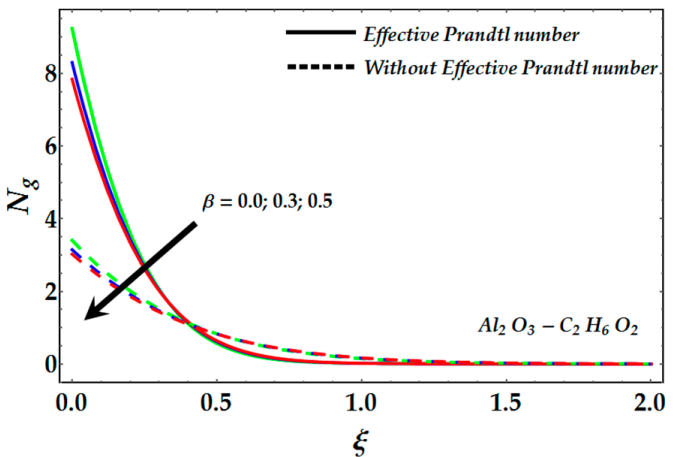

(b)

Figure 7. Entropy generation number for different values of $\beta$. (a) For $\mathrm{Al}_{2} \mathrm{O}_{3}-\mathrm{H}_{2} \mathrm{O}$, (b) $\mathrm{For}_{2} \mathrm{Al}_{2} \mathrm{O}_{3}-\mathrm{C}_{2} \mathrm{H}_{6} \mathrm{O}_{2}$.

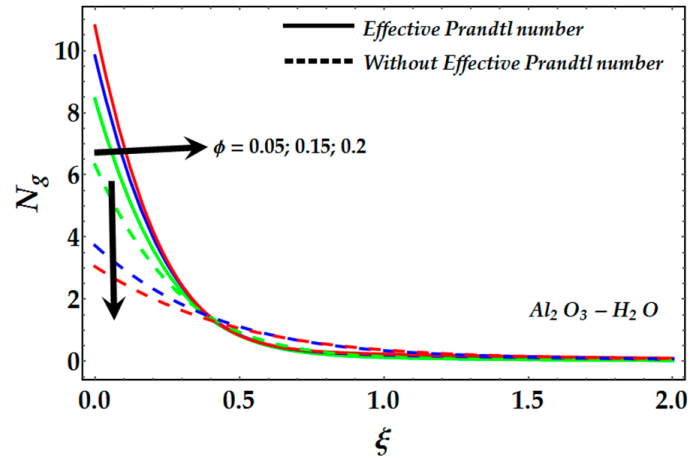

(a)

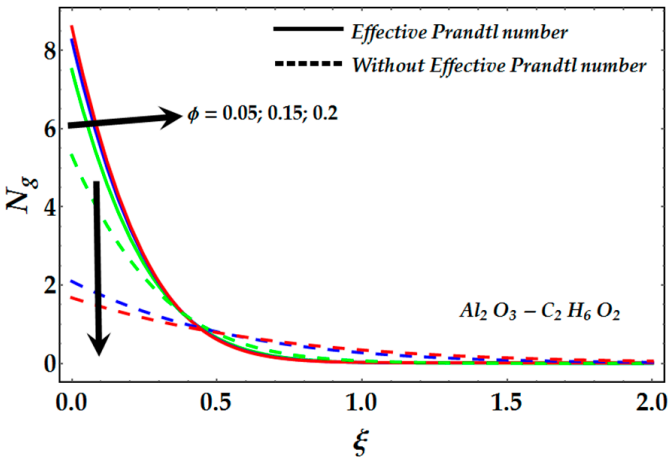

(b)

Figure 8. Entropy generation number for different values of $\phi$. (a) For $\mathrm{Al}_{2} \mathrm{O}_{3}-\mathrm{H}_{2} \mathrm{O}$, (b) For $\mathrm{Al}_{2} \mathrm{O}_{3}-\mathrm{C}_{2} \mathrm{H}_{6} \mathrm{O}_{2}$. 
Figure 9 is sketched for different values of Brinkmann number $\mathrm{Br}$ and temperature difference $\Omega$. It is seen from this figure that the entropy profile increases for higher values of $B r / \Omega$. However, for $\gamma \mathrm{Al}_{2} \mathrm{O}_{3}-\mathrm{C}_{2} \mathrm{H}_{6} \mathrm{O}_{2}$ nanofluid, the variation in entropy profile is very small. Figure 10 shows that an increment in Reynolds number Re markedly enhances the entropy profile due to heat transfer in a boundary layer and nanofluid friction for both $\gamma \mathrm{Al}_{2} \mathrm{O}_{3}-\mathrm{C}_{2} \mathrm{H}_{6} \mathrm{O}_{2}$ and $\gamma \mathrm{Al}_{2} \mathrm{O}_{3}-\mathrm{H}_{2} \mathrm{O}$ nanofluids. An increment in Reynolds number causes a disturbance in the flow field and then chaos occurs in the movement of fluid. The presence of an effective Prandtl number enhances the entropy profile.

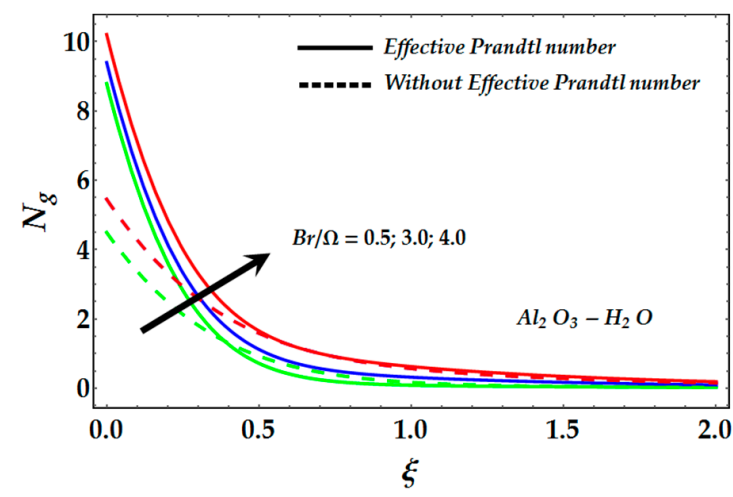

(a)

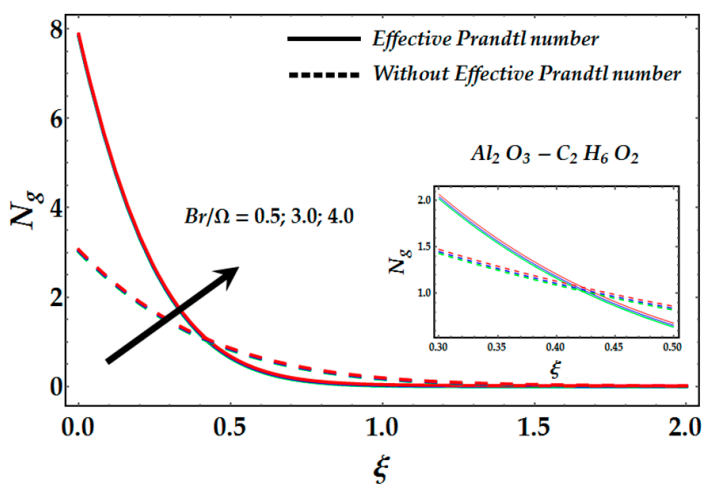

(b)

Figure 9. Entropy generation number different values of $\mathrm{Br} / \Omega$. (a) For $\mathrm{Al}_{2} \mathrm{O}_{3}-\mathrm{H}_{2} \mathrm{O}$, (b) For $\mathrm{Al}_{2} \mathrm{O}_{3}-\mathrm{C}_{2} \mathrm{H}_{6} \mathrm{O}_{2}$.

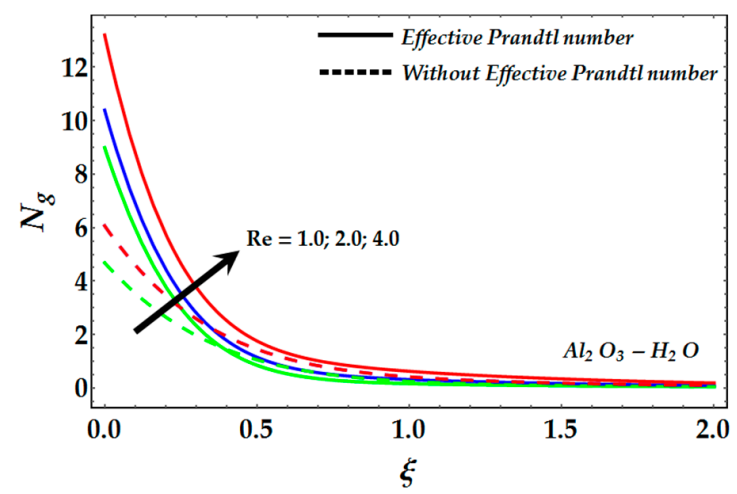

(a)

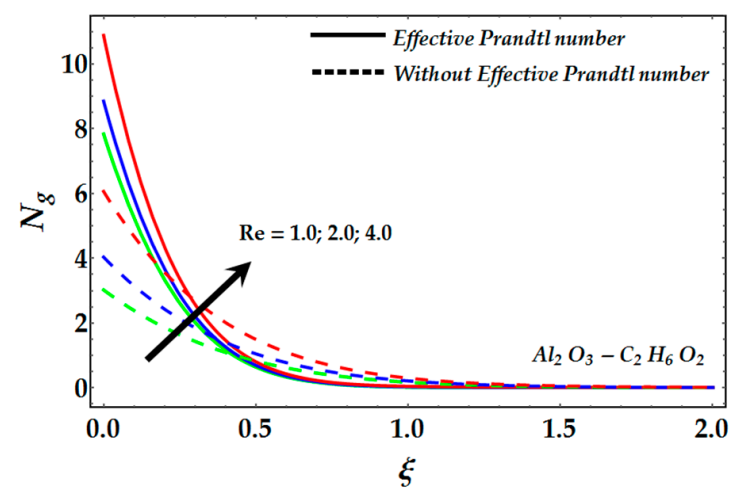

(b)

Figure 10. Entropy generation number for different values of Re. (a) For $\mathrm{Al}_{2} \mathrm{O}_{3}-\mathrm{H}_{2} \mathrm{O}$, (b) For $\mathrm{Al}_{2} \mathrm{O}_{3}-\mathrm{C}_{2} \mathrm{H}_{6} \mathrm{O}_{2}$.

\section{Conclusions}

In this article, we have considered the slip effects on nanofluid flow through a stretching sheet in the absence and presence of an effective Prandtl number. A numerical technique (STSLM) with the combination of the Chebyshev spectral collocation method has been used to obtain the numerical solutions. A good numerical comparison with previously published results has been presented to validate the current methodology and results. The current investigation leads to the following important conclusions:

i. An increment in nanoparticle volume fraction causes a marked increment in the velocity of nanofluids.

ii. Slip effects tend to provide a significant resistance in the velocity profile for both $\gamma \mathrm{Al}_{2} \mathrm{O}_{3}-\mathrm{C}_{2} \mathrm{H}_{6} \mathrm{O}_{2}$ and $\gamma \mathrm{Al}_{2} \mathrm{O}_{3}-\mathrm{H}_{2} \mathrm{O}$ nanofluids. The existence of Prandtl number tends to diminish the velocity profile.

iii. A remarkable reduction occurs in the temperature profile by increasing the Prandtl number for both $\gamma \mathrm{Al}_{2} \mathrm{O}_{3}-\mathrm{C}_{2} \mathrm{H}_{6} \mathrm{O}_{2}$ and $\gamma \mathrm{Al}_{2} \mathrm{O}_{3}-\mathrm{H}_{2} \mathrm{O}$ nanofluids. 
iv. The impact of slip conditions significantly enhances the temperature profile in the presence and absence of an effective Prandtl number.

v. The temperature profile is enhanced due to nanoparticle volume fraction in the absence of an effective Prandtl number, whereas the converse behavior is seen in the presence of an effective Prandtl number.

vi. Due to the increment in slip parameter the entropy profile decreases whereas an effective Prandtl number enhances entropy generation.

vii. Reynolds number and Brinkmann number also enhance the entropy profile and a similar relation has been observed in the presence of an effective Prandtl number.

Acknowledgments: We express our gratitude to anonymous referees for their constructive reviews of the muniscript and for helpful comments.

Author Contributions: Mohammad Mehdi Rashidi conceived and designed the mathematical formulation of the problem, whereas solution of the problem and graphical results is analyzed by Munawwar Ali Abbas. All authors have read and approved the final manuscript.

Conflicts of Interest: The authors declare no conflict of interest.

\section{Nomenclature}

$\begin{array}{ll}\check{T}_{w} & \text { Temperature of wall } \\ \operatorname{Pr}_{n f} & \text { Nanofluid, Prandtl number } \\ \mathrm{g}, \mathrm{m} / s^{2} & \text { Gravity } \\ k_{n f} & \text { Nanofluid, thermal conductivity } \\ \check{T} & \text { Nanofluid temperature } \\ \operatorname{Pr}_{f} & \text { Base fluid Prandtl number } \\ N u_{x} & \text { Nusselt number of nano fluid } \\ C_{f} & \text { skin friction coefficient } \\ k_{f} & \text { Base fluid, thermal conductivity } \\ \breve{T}_{\infty} & \text { ambient temperature } \\ \widetilde{u}, \widetilde{v} \mathrm{~m} / \mathrm{s} & \text { Expression of velocity in horizontal and vertical directions, Respectively } \\ k_{s} & \text { Nanoparticles, thermal conductivity }\end{array}$

\section{Greek Symbols}

$\begin{array}{ll}\lambda & \text { parameter of mixed convection } \\ \phi & \text { volume fraction of the model } \\ \rho_{n f} & \text { nanofluid effective density } \\ \mu_{n f} & \text { viscosity of the nanofluid effective dynamic } \\ (\rho \beta)_{s} & \text { coefficient of Nanoparticles thermal expansion } \\ \mu_{f} & \text { the base fluid dynamic viscosity } \\ (\rho \beta)_{f} & \text { Base fluid thermal expansion coefficient } \\ \rho_{s} & \text { Nanoparticles density } \\ \rho_{f} & \text { base fluid density } \\ (\rho \beta)_{n f} & \text { nanofluid thermal expansion coefficient } \\ \xi & \text { variable of space }\end{array}$

\section{References}

1. Chol, S.U.S.; Eastman, J.A. Enhancing thermal conductivity of fluids with nanoparticles. ASMEPublications-Fed 1995, 231, 99-106.

2. Masuda, H.; Ebata, A.; Teramae, K.; Hishinunma, N.; Ebata, Y. Alteration of thermal conductivity and viscosity of liquid by dispersing ultra-fine particles (dispersion of $\gamma-\mathrm{Al}_{2} \mathrm{O}_{3}, \mathrm{SiO}_{2}$ and $\mathrm{TiO}_{2}$ ultra-fine particles). Netsu Bussei 1993, 7, 227-233. (In Janpanese) [CrossRef]

3. Buongiorno, J. Convective transport in nanofluids. J. Heat Transf. 2006, 128, 240-250. [CrossRef] 
4. Khan, W.A.; Pop, I. Boundary-layer flow of a nanofluid past a stretching sheet. Int. J. Heat Mass Transf. 2010, 53, 2477-2483. [CrossRef]

5. Makinde, O.D.; Khan, W.A.; Khan, Z.H. Buoyancy effects on MHD stagnation point flow and heat transfer of a nanofluid past a convectively heated stretching/shrinking sheet. Int. J. Heat Mass Transf. 2013, 62, 526-533. [CrossRef]

6. Nadeem, S.; Haq, R.; Khan, Z.H. Numerical study of MHD boundary layer flow of Maxwell fluid past a stretching sheet in the presence of nanoparticles. J. Taiwan Inst. Chem. Eng. 2014, 45, 121-126. [CrossRef]

7. Malik, M.Y.; Khan, I.; Hussain, A.; Salahuddin, T. Mixed convection flow of MHD Eyring-Powell nanofluid over a streching sheet: A numerical study. AIP Adv. 2015, 5, 117-118. [CrossRef]

8. Raju, C.S.K.; Sandeep, N. Unsteady Casson nano over a rotating cone in a rotating frame filled with ferrous nanoparticles: A numerical study. J. Magn. Magn. Mater. 2017, 421, 216-224. [CrossRef]

9. Nadeem, S.; Saleem, S. Analytical study of third grade fluid over a rotating vertical cone in thepresence of nanoparticles. Int. J. Heat Mass Transf. 2015, 85, 1041-1048. [CrossRef]

10. Raju, C.S.K.; Sandeep, N.; Malvandi, A. Free convective heat and mass transfer of MHD Non-Newtonian nanofluids over a cone in the presence of non-uniform heat soure/sink. J. Mol. Liq. 2016, 221, 108-115. [CrossRef]

11. Nadeem, S.; Saleem, S. Unsteady mixed convection flow of nanofluid on a rotating cone with magnetic field. Appl. Nanosci. 2014, 4, 405-414. [CrossRef]

12. Bhatti, M.M.; Rashidi, M.M. Effects of thermo-diffusion and thermal radiation on Williamson nanofluid over a porous shrinking/stretching sheet. J. Mol. Liq. 2016, 221, 567-573. [CrossRef]

13. Nadeem, S.; Haq, R.; Khan, Z.H. Numerical solution of non-Newtonian nanofluid flow over a stretching sheet. Appl. Nanosci. 2014, 4, 625-631. [CrossRef]

14. Hsiao, K.L. Combined electrical MHD heat transfer thermal extrusion system using Maxwell fluid with radiative and viscous dissipation effects. Appl. Therm. Eng. 2017, 112, 1281-1288. [CrossRef]

15. Hsiao, K.L. To promote radiation electrical MHD activation energy thermal extrusion manufacturing system efficiency by using Carreau-Nanofluid with parameters control method. Energy 2017, 130, 486-499. [CrossRef]

16. Zhang, C.; Zheng, L.; Zhang, X.; Chen, G. MHD flow and radiation heat transfer of nanofluids in porous media with variable surface heat flux and chemical reaction. Appl. Math. Model. 2015, 39, 161-184. [CrossRef]

17. Nield, D.A.; Kuznetsov, A.V. The Cheng-Minkowycz problem for natural convective boundary-layer flow in a porous medium saturated by a nanofluid. Int. J. Heat Mass Transf. 2009, 52, 5792-5795. [CrossRef]

18. Rahman, M.M.; Roşca, A.V.; Pop, I. Boundary layer flow of a nanofluid past a permeable exponentially shrinking/stretching surface with second order slip using Buongiorno's model. Int. J. Heat Mass Transf. 2014, 77, 1133-1143. [CrossRef]

19. Bhatti, M.M.; Shahid, A.; Rashidi, M.M. Numerical simulation of Fluid flow over a shrinking porous sheet by Successive linearization method. Alexandria Eng. J. 2016, 55, 51-56. [CrossRef]

20. Hsiao, K.L. Stagnation electrical MHD nanofluid mixed convection with slip boundary on a stretching sheet. Appl. Therm. Eng. 2016, 98, 850-861. [CrossRef]

21. Hsiao, K.L. Numerical solution for Ohmic Soret-Dufour heat and mass mixed convection of viscoelastic fluid over a stretching sheet with multimedia physical features. J. Aerosp. Eng. 2016, 30, 04016082. [CrossRef]

22. Shahid, A.; Bhatti, M.M.; Bég, O.A.; Kadir, A. Numerical study of radiative Maxwell viscoelastic magnetized flow from a stretching permeable sheet with the Cattaneo-Christov heat flux model. Neural Comput. Appl. 2017. [CrossRef]

23. Mishra, S.R.; Bhatti, M.M. Simultaneous effects of Chemical reaction and Ohmic heating with heat and mass transfer over a stretching surface: A numerical study. Chin. J. Chem. Eng. 2017. [CrossRef]

24. Hsiao, K.L. Micropolar nanofluid flow with MHD and viscous dissipation effects towards a stretching sheet with multimedia feature. Int. J. Heat Mass Transf. 2017, 112, 983-990. [CrossRef]

25. Bejan, A. Entropy generation minimization: The new thermodynamics of finite-size devices and finite-time processes. J. Appl. Phys. 1996, 79, 1191-1218. [CrossRef]

26. Abbas, M.A.; Bai, Y.; Rashidi, M.M.; Bhatti, M.M. Analysis of entropy generation in the flow of peristaltic nanofluids in channels with compliant walls. Entropy 2016, 18, 90. [CrossRef]

27. Abolbashari, M.H.; Freidoonimehr, N.; Nazari, F.; Rashidi, M.M. Analytical modeling of entropy generation for Casson nano-fluid flow induced by a stretching surface. Adv. Powder Technol. 2015, 26, 542-552. [CrossRef] 
28. Qing, J.; Bhatti, M.M.; Abbas, M.A.; Rashidi, M.M.; Ali, M.E.S. Entropy generation on MHD Casson nanofluid flow over a porous stretching/shrinking surface. Entropy 2006, 18, 123. [CrossRef]

29. Bhatti, M.M.; Rashidi, M.M.; Pop, I. Entropy Generation with nonlinear heat and Mass transfer on MHD Boundary Layer over a Moving Surface using SLM. Nonlinear Eng. 2017, 6, 43-52. [CrossRef]

30. Rashidi, M.M.; Bhatti, M.M.; Abbas, M.A.; Ali, M.E.S. Entropy generation on MHD blood flow of nanofluid due to peristaltic waves. Entropy 2016, 18, 117. [CrossRef]

31. Rashidi, M.M.; Bagheri, S.; Momoniat, E.; Freidoonimehr, N. Entropy analysis of convective MHD flow of third grade non-Newtonian fluid over a stretching sheet. Ain Shams Eng. J. 2015. [CrossRef]

32. Bhatti, M.M.; Abbas, T.; Rashidi, M.M. Entropy generation as a practical tool of optimisation for non-Newtonian nanofluid flow through a permeable stretching surface using SLM. J. Comput. Des. Eng. 2017, 4, 21-28. [CrossRef]

33. Lee, S.; Choi, S.U.-S.; Li, S.; Eastman, J.A. Measuring thermal conductivity of fluids containing oxide nanoparticles. J. Heat Transf. 1999, 121, 280-289. [CrossRef]

34. Wang, X.; Xu, X.; Choi, S.U.-S. Thermal conductivity of nanoparticles-fluid mixture. J. Thermophys. Heat Transf. 1999, 13, 474-480. [CrossRef]

35. Hamilton, R.L.; Crosser, O.K. Thermal conductivity of heterogeneous two component systems. Ind. Eng. Chem. Fundam. 1962, 1, 187-191. [CrossRef]

36. Maiga, S.E.B.; Nguyen, C.T.; Galanis, N.; Roy, G. Heat transfer behaviors of nanofluids in a uniformly heated tube. Superlattices Microstruct. 2004, 35, 543-557. [CrossRef]

37. Pop, C.V.; Fohanno, S.; Polidori, G.; Nguyen, C.T. Analysis of laminar-to-turbulent threshold with water c $\mathrm{Al}_{2} \mathrm{O}_{3}$ and ethylene glycol-c $\mathrm{Al}_{2} \mathrm{O}_{3}$ nanofluids in free convection. In Proceedings of the 5th IASME/WSEAS International Conference on Heat Transfer, Thermal Engineering and Environment, Athens, Greece, 25-27 August 2017; p. 188.

38. Bhatti, M.M.; Rashidi, M.M. Entropy generation with nonlinear thermal radiation in MHD boundary layer flow over a permeable shrinking/stretching sheet: Numerical solution. J. Nanofluids 2016, 5, 543-548. [CrossRef]

39. Bhatti, M.M.; Abbas, T.; Rashidi, M.M. Numerical Study of Entropy Generation with Nonlinear Thermal Radiation on Magnetohydrodynamics non-Newtonian Nanofluid Through a Porous Shrinking Sheet. J. Magn. 2016, 21, 468-475. [CrossRef]

40. Bhatti, M.M.; Rashidi, M.M. Numerical simulation of entropy generation on MHD nanofluid towards a stagnation point flow over a stretching surface. Int. J. Appl. Comput. Math. 2017, 3, 2275-2289. [CrossRef]

41. Abbas, T.; Ayub, M.; Bhatti, M.M.; Rashidi, M.M.; Ali, M.E.S. Entropy generation on nanofluid flow through a horizontal Riga plate. Entropy 2016, 18, 223. [CrossRef]

42. Bhatti, M.M.; Abbas, T.; Rashidi, M.M.; Ali, M.E.S.; Yang, Z. Entropy generation on MHD Eyring-Powell nanofluid through a permeable stretching surface. Entropy 2016, 18, 224. [CrossRef]

43. Bhatti, M.M.; Abbas, T.; Rashidi, M.M.; Ali, M.E.S. Numerical simulation of entropy generation with thermal radiation on MHD Carreau nanofluid towards a shrinking sheet. Entropy 2016, 18, 200. [CrossRef]

44. Ali, M.E. Heat transfer characteristics of a continuous stretching surface. Heat Mass Transf. 1994, 429, $227-234$. [CrossRef]

45. Grubka, L.J.; Bobba, K.M. Heat transfer characteristics of a continuous, stretching surface with variable temperature. ASME J. Heat Transf. 1985, 107, 248-250. [CrossRef]

46. Ishak, A.; Nazar, R.; Pop, I. Boundary layer flow and heat transfer over an unsteady stretching vertical surface. Meccanica 2009, 44, 369-375. [CrossRef]

(C) 2017 by the authors. Licensee MDPI, Basel, Switzerland. This article is an open access article distributed under the terms and conditions of the Creative Commons Attribution (CC BY) license (http:/ / creativecommons.org/licenses/by/4.0/). 